\title{
Differential Expression of the Lactose Transporter Gene Affects Growth of Staphylococcus aureus in Milk
}

\author{
M. V. Sharer, C. Su, N. V. Hegde, B. M. Jayarao, and L. M. Sordillo \\ Department of Veterinary Science \\ The Pennsylvania State University \\ University Park 16802
}

\section{ABSTRACT}

In this study, differential display polymerase chain reaction (PCR) was used to search for unique or enhanced expression of genes in prevalent bovine mastitis-causing Staphylococcus aureus strains. Comparison of a pair of prevalent and rare strains revealed the differential expression of several genes. The lactosespecific permease, enzyme II (EII), was highly expressed in the prevalent strain. This gene was selected for further study due to its potential influence on bacterial growth, because lactose is the primary carbohydrate in milk. Growth analysis illustrated that prevalent strains reach significantly higher growth densities sooner than rare strains. Quantitative competitive reverse transcription PCR (QC RT-PCR) revealed increased EII mRNA expression in prevalent strains as compared to rare strains. Mutation of the EII gene resulted in abrogated growth and decreased EII mRNA expression in media containing lactose. These data suggest that increased EII expression may facilitate the pathogenesis of $S$. aureus mastitis by enhancing growth. This study is the first to implicate EII as a potential virulence factor in mastitis, and therefore may be useful in the development of novel therapeutic strategies against $S$. aureus mastitis.

(Key words: lactose transporter, Staphylococcus aureus, mastitis)

Abbreviation key: $\boldsymbol{a g r}$ = accessory gene regulator, BLAST = Basic Local Alignment Search Tool, CcpA = catabolite control protein, $\mathbf{C m}=$ chloramphenicol, dNTP = deoxynucleotide triphosphate, $\mathbf{E I I}=$ enzyme II, GAPDH = glyceraldehyde-3-phosphate dehydrogenase, $\boldsymbol{l a c}=$ lactose operon, $\mathbf{M M L V - R T}=$ moloney $\mathrm{mu}$ rine leukemia virus reverse-transcriptase, $\mathbf{O R F}=$ open reading frame, PTS = phosphotransferase system, QC RT-PCR = quantitative-competitive reverse-tran-

Received December 11, 2002.

Accepted January 24, 2003.

Corresponding author: L. M. Sordillo; e-mail: lms10@psu.edu. scriptase PCR, TSA = tryptic soy agar, $\mathbf{T S B}=$ tryptic soy broth, TSST-1 = toxic shock syndrome toxin-1.

\section{INTRODUCTION}

Strain typing has become a powerful tool for investigating the epidemiology of bacterial infections. Staphylococcus aureus strains have been subtyped by a wide variety of methods including: phage typing, ribotyping, plasmid analysis, pulse-field gel electrophoresis of genomic DNA fragments, multilocus enzyme electrophoresis, random amplified polymorphic DNA, and coagulase gene typing (Slanetz and Bartley, 1962; Baumgartner et al., 1984; Thomson-Carter et al., 1989; Musser et al., 1990; Goh et al., 1992; Saulnier et al., 1993; Matthews, 1994). Our laboratory utilized restriction fragment length polymorphism to subtype $S$. aureus strains obtained from clinical cases of mastitis from various countries, based on the coagulase gene (Aarestrup et al., 1995; Su et al., 1999). It was determined that only a few genotypes abound from each geographical location tested (Su et al., 1999). Further experiments showed that these predominant genotypes were significantly more resistant to neutrophil killing than rare genotypes (Su et al., 1999; Mullarky et al., 2001). Consequently, it was hypothesized that these prevalent strains may differentially express certain genes that better enable them to overcome essential host defense mechanisms and successfully colonize mammary tissue. Therefore, we utilized differential display to identify potential virulence factors produced by these prevalent $S$. aureus strains. Differential display was originally developed by Liang and Pardee to identify differentially expressed genes among two or more eukaryotic cell populations (Liang and Pardee, 1992). Since then, differential display has been successfully employed to identify candidate virulence factors in bacteria (Rindi et al., 1999; Achour et al., 2002). The ability to identify novel virulence genes would greatly improve our understanding of mastitis virulence.

Mastitis infection by $S$. aureus is a complex process involving many bacterial factors (Sutra and Poutrel, 1994). Bacterial growth is one such factor, and is sig- 
nificant in the virulence of mastitis-causing $S$. aureus (Chesbro et al., 1968; White et al., 1980; Odierno et al., 1994). While the mechanism by which growth affects virulence is not yet fully understood, recent studies are beginning to elucidate its role. One study recently demonstrated that growth is required for the production of the superantigen, toxic shock syndrome toxin-1 (TSST-1) (Timmins and Holland, 1999). They found that as $S$. aureus shifts down in growth rate during entry into the stationary phase of growth, TSST-1 increases considerably. Furthermore, growth is known to play a role in the regulation of virulence factors through the accessory gene regulator (agr) (Novick et al., 1993). Staphylococcus aureus is able to sense its growth density through the interaction of a quorum sensing mechanism produced by the agr locus (Peng et al., 1988). Consequently, $S$. aureus is able to express surface-associated products during early exponential phase and extracellular factors during postexponential phase (Novick et al., 1993). Therefore, any contribution to growth is likely to have a direct effect on virulence.

To metabolize carbohydrates and grow, many bacteria utilize the phosphoenol pyruvate-dependent phosphotransferase system (PTS), which couples translocation to phosphorylation of the transported carbohydrates (Postma et al., 1993; Lengeler et al., 1994). The $S$. aureus lactose-specific enzyme EII of the PTS, encoded by $l a c E$, selectively transports lactose across the bacterial membrane (Reizer et al., 1988). EIII (lacF) phosphorylates lactose before it is cleaved into glucose and galactose-6-phosphate by phospho- $\beta$-galactosidase (lacG) (Hengstenberg et al., 1970). Lactose and galactose have been shown to induce the lactose operon (lac), although the common byproduct of their catabolism, galactose-6-phosphate, is the actual intracellular inducer (Morse et al., 1968). The lac operon is also subject to catabolite repression by the lac repressor, thus its expression is based on carbohydrate source (Oskouian and Stewart, 1990). Because EII plays such an important role in lactose metabolism, we hypothesized that the differential expression of EII can affect growth of $S$. aureus in a lactose-rich microenvironment, such as milk. Because growth has long been implicated in the virulence of $S$. aureus mastitis, influencing growth could have a significant impact (Chesbro et al., 1968; White et al., 1980; Odierno et al., 1994). To date, no studies have investigated the impact of EII expression on growth as it relates to mastitis. Understanding the relationship between carbohydrate metabolism and virulence may lead to the development of novel prevention strategies.

\section{MATERIALS AND METHODS}

\section{Bacterial Strains}

Before this study, a collection of $453 \mathrm{~S}$. aureus isolates were obtained from samples of bovine mastitic milk, which were acquired from a variety of geographical locations (the Czech Republic, France, Korea, and the United States). These isolates were subtyped into 40 types by restriction fragment length polymorphism, using the coagulase gene. Only a few genotypes predominated in each country (Su et al., 1999). Staphylococcus aureus strains used in the present study were considered prevalent if their genotype represented $40 \%$ or more of the isolates from one country. Conversely, strains were considered rare if their genotypes represented less than $10 \%$ of the isolates from one country. From this collection, a prevalent (A4) and rare strain (L42) were used for differential display PCR. For growth curves and EII mRNA expression, a total of 18 $S$. aureus strains were selected from both prevalent ( $n$ $=9)$ and rare $(n=9)$ genotypes. Prevalent strain, CZ8, was later selected for mutagenesis. All isolates were cultured in trypticase soy agar (TSA) with $5 \%$ sheep blood (BiMed, St. Paul, MN), and stored at $-70^{\circ} \mathrm{C}$ in trypticase soy broth (TSB) with $15 \%$ glycerol until needed.

\section{RNA Preparation and Differential Display PCR}

Total RNA was collected from $S$. aureus strains and purified using Trizol reagent according to manufacturer's instructions (Life Technologies, Baltimore, MD). The total RNA samples were then treated with RNAsefree DNAse to eliminate DNA contamination. To enrich mRNA concentration, rRNA was subtracted from total RNA samples as described previously (Su and Sordillo, 1998). The pair of $S$. aureus strains used for differential display was grown in UHT milk for $5 \mathrm{~h}$ at $37^{\circ} \mathrm{C}$, and the mRNA was isolated. The arbitrary primers used in this study are listed in Table 1 . A total of 30 pairs of primers were designed for differential display PCR. The first primer of each set was used as a primer for reverse transcription to generate cDNA from mRNA (Table 1). To generate cDNA for PCR, $200 \mathrm{ng}$ of mRNA was first denatured at $70^{\circ} \mathrm{C}$ and reverse transcribed into cDNA at $42^{\circ} \mathrm{C}$ for $1 \mathrm{~h}$. The reaction mixture contained $1 \times$ reverse transcription buffer, $0.25 \mu M$ of an arbitrary primer, $2.5 \mathrm{~m} M$ of each deoxynucleotide triphosphate (dNTP) , $40 \mathrm{U}$ of ribonuclease inhibitor, and $200 \mathrm{U}$ of moloney murine leukemia virus reverse transcriptase (MMLV-RT). After reverse transcription, mRNA was digested by ribonuclease $\mathrm{H}$. The PCR was performed in a volume of $25 \mu \mathrm{l}$ with $1 \times$ PCR buffer, $0.4 \mu M$ of the primer used for reverse transcription, $0.4 \mu M$ of the second arbitrary primer, $2 \mu \mathrm{l}$ of reverse transcription products, $2.5 \mathrm{mM}$ of $\mathrm{MgCl}_{2}, 0.4 \mathrm{mM}$ of each dNTP, 0.5 $\mu \mathrm{Ci}$ of ${ }^{32} \mathrm{P} \mathrm{dCTP}$, and $1 \mathrm{U}$ of Taq DNA Polymerase (Promega, Madison, WI). The cycling conditions were $94^{\circ} \mathrm{C}(1 \mathrm{~min}), 30^{\circ} \mathrm{C}(2 \mathrm{~min}), 72^{\circ} \mathrm{C}(2.5 \mathrm{~min})$ for 40 cycles. 
Table 1. Differential display arbitrary primers.

\begin{tabular}{ll}
\hline Primer ID & Sequences \\
\hline DP1 & TGCCTAATAATGCTAAAC \\
DP2 & AGGGCGTGGTGCGGAGGGCGGT \\
DP3 & TCGGGGATGGGAGTGCTAATG \\
DP4 & TGGCTATGTGCTATGGGTCTTT \\
DP5 & ATGAAAAATGCTGGGCTTGGAGA \\
DP6 & CCACGCGTGTGTGTGAAA \\
DP7 & GAGGGCGGTGGCAGGAGTTAGG \\
DP8 & AGGCCGTGTACTCCGTGATGG \\
DP9 & GCTAAGGAGGCAGAGGGTGA \\
DP11 & GGCCGAGGGTGCTGGAGTTT \\
DP16 & TCGGGGATGGGAGTGCTA \\
DP17 & ATGAGGAAGACCAGGAAGAAGC \\
DP18 & AAATGCTGAATAATCCGC \\
DP22 & TACAGCATCATCTTTGTCTCG \\
DP23 & ATCTTGATGTCCACACAGAT
\end{tabular}

The following 30 primer sets were used for differential display PCR: DPl/DP6, DPl/DP8, DP2/DP3, DP2/DP7, DP3/DPl, DP3/DP5, DP3/ DPI6, DP4/DP2, DP4/DPll, DP4/DP8, DP4/DP9, DP5/DPl, DP5/DP2, DP5/DP8, DP5/DP9, DP6/DP9, DP7/DP4, DP7/DP5, DP7/DP17, DP8/ DPl, DP8/DP4, DP8/DP5, DP8/DP9, DP8/DPI8, DP9/DP2, DP9/DPll, DP22/DP2, DP22/DP4, DP23/DPl, DP23/DP2.

The PCR products were separated on a $6 \%$ polyacrylamide gel. After gel electrophoresis, the gel was dried and exposed to X-ray film at $-70^{\circ} \mathrm{C}$. Differentially amplified PCR products existing in all RNA preparations from three separate differential displays were then reamplified by PCR using the corresponding primers. The cycling conditions were $94^{\circ} \mathrm{C}(1 \mathrm{~min}), 60^{\circ} \mathrm{C}(1 \mathrm{~min})$, and $72^{\circ} \mathrm{C}(1.5 \mathrm{~min})$ for 30 cycles. The reamplified PCR products were cloned and used directly to generate probes for Northern blot analysis.

\section{Northern Blot Analysis of Selected Differentially Expressed Genes}

To confirm the findings in differential display PCR, Northern blot analysis was performed. Total RNA (10 $\mu \mathrm{g})$ was electrophoresed in formaldehyde gels (1.2\%). The RNA was then transferred to a Nytran membrane and cross-linked with UV radiation. DNA probes were labeled with ${ }^{32} \mathrm{P}$ (Amersham Pharmacia Biotech, Piscataway, NJ) using Prime-a-Gene Labeling System (Promega, Madison, WI). After hybridization at $68^{\circ} \mathrm{C}$ for 2 $\mathrm{h}$, the membrane was washed and X-ray film exposed at $-70^{\circ} \mathrm{C}$. After confirmation by Northern blot analysis, differentially expressed genes were sequenced by cycle sequencing (Protein and DNA Chemistry Services, Biotechnology Institute and Bioprocessing Resource Center, 210 Wartik lab, University Park, PA). To determine the identity of the DNA sequences, Basic Local Alignment Search Tool (BLAST) search was conducted against the GenBank database (Altschul et al., 1990).

\section{QC RT-PCR of Ell mRNA}

The forward and reverse EII primers were: $\left(5^{\prime}\right.$-CAG GAACGACAGCGAAATCTT- $3^{\prime}$ ) and ( $5^{\prime}$-GCTGTTGCG AATGACTAAATCTAA-3'). The EII internal standard primers using glyceraldehyde-3-phosphate dehydrogenase (GAPDH) were: ISfor(5'-TAATACGACTCACTA TAGGCGAGGAACGACAGCGAAATCTTGCATGGC CTTCCGTGTCC-3'), andISrev(5'-TTTTTTTTTTTTTT TTGCTGTTGCGAATGACTAAATCTAACAGCCCCA GCGTCAAAGGTG-3'). Staphylococcus aureus RNA (1 $\mu \mathrm{g})$ was added to a RT mixture containing the following: $1 \mu \mathrm{g}$ of $10^{8}$ molecules of competing RNA internal standard (GAPDH), $5 \times$ MMLV buffer, $10 \mathrm{~m} M$ dNTP, 25 $\mathrm{mM} \mathrm{MgCl} 2,10 \mathrm{U}$ of MMLV-RT, $150 \mu \mathrm{g}$ of oligo dT, and $8 \mathrm{U}$ of RNasin. Each sample was incubated for $45 \mathrm{~min}$ at $37^{\circ} \mathrm{C}$ and $5 \mathrm{~min}$ at $95^{\circ} \mathrm{C}$. Five microliters of the RT mixture was then added to a PCR mixture containing the following: $10 \times \mathrm{NEB}$ buffer, $25 \mathrm{mM} \mathrm{MgCl}, 10 \mathrm{pmol}$ of forward and reverse EII primers, and $1 \mathrm{U}$ of Taq polymerase. Thermal cycling parameters were $95^{\circ} \mathrm{C}(5$ min) for 1 cycle; $94^{\circ} \mathrm{C}(10 \mathrm{~s}), 60^{\circ} \mathrm{C}(30 \mathrm{~s}), 72^{\circ} \mathrm{C}(45 \mathrm{~s})$ for 30 cycles; and $72^{\circ} \mathrm{C}(5 \mathrm{~min})$ for 1 cycle. RT-PCR products were then electrophoresed on $1.8 \%$ agarose gels and detected in the presence of ethidium bromide under UV illumination.

\section{Growth Analysis}

Overnight cultures of $S$. aureus strains were adjusted to an $\mathrm{A}_{540}$ of 0.01 and inoculated into either UHT milk or TSB containing the following changes: a) $136 \mathrm{mM}$ lactose, b) $13.89 \mathrm{~m} M$ lactose, c) $13.89 \mathrm{~m} M$ glucose, or d) $13.89 \mathrm{~m} M$ lactose plus $13.89 \mathrm{~m} M$ glucose. Bacterial cultures were grown for $12 \mathrm{~h}$ at $37^{\circ} \mathrm{C}$ while shaking at $150 \mathrm{rpm}$. Aliquots taken every hour were serially diluted and plated on TSA.

\section{Ell Mutagenesis}

The $S$. aureus lacE gene was interrupted using the chloramphenicol $(\mathbf{C m})$ resistance gene. The lacE, a 2040-bp fragment containing the entire lacE sequence was PCR amplified, digested with BamHI, and ligated into pUC18: EIIKO1 (5'-GTTGGGATCCCAGGGGAT GCACGTTCTAAGT -'3) and EIIKO2 (5'-TTTCGGAT CCATACGTATCCCATGCTACGCGACC-'3). The Cm gene was PCR amplified from pACYC184 (New England Biolabs, Beverly, MA) using primers containing SpeI sites: CM1 (5'-TGGCACTAGTGAGACGTTGATC GGCACGTA-' 3 ) and CM2 (5'-TAACACTAGTGCCCTG AACCGACGACCGGG-'3). The Cm fragment was digested and ligated into the SpeI site of the cloned lacE fragment. The lacE::Cm fragment was then ligated into BamHI site of pCL52.1, and transformed into E. coli 
DH5 $\alpha$ while selecting for with spectinomycin $(50 \mu \mathrm{g} /$ $\mathrm{ml}$ ) (Lin et al., 1994). The resulting plasmid was electroporated into $S$. aureus strain, RN4220 (Kreiswirth et al., 1983), selected for with tetracycline $(20 \mu \mathrm{g} / \mathrm{ml})$ and incubated at $30^{\circ} \mathrm{C}$. The $l a c E$ mutant construct was finally transformed into prevalent strain, CZ8, via electroporation. Allelic exchange proceeded as previously described (Lin et al., 1994). Tetracycline-sensitive colonies were grown at $37^{\circ} \mathrm{C}$ and screened by PCR, using primers: EIIKOTEST1 (5'-TGGAGAACACGCAGATA AAA-3') and EIIKOTEST2 (5'-TAGGAATGGGTAGTA AATAATAA- $\left.3^{\prime}\right)$. Mutations were confirmed by PCR. Phospho- $\beta$-galactosidase assays were performed as previously described by Oskouian (Oskouian and Stewart, 1987), to determine whether the mutation in EII disrupted lactose transport.

\section{Statistical Analysis}

Significant differences between growth rates of prevalent and rare strains were determined with one-way ANOVAs using the Minitab (State College, PA) statistical program. The Student's two-sample $t$-test was used to determine significant differences among EII transcripts and specific time points during the growth analyses. Statistical significance was set as $P<0.05$.

\section{RESULTS}

\section{Differential Display Identifies Ell as Having a Potential Effect on Growth in Milk}

A total of 30 pairs of arbitrary primers were tested in this study (Table 1). Based on the fact that $S$. aureus has a genomic DNA of $2.8 \mathrm{Mbp}$, and assuming the average gene size is $1500 \mathrm{bp}$, there would be approximately 2000 genes available. Assuming each pair of primers can generate 10 PCR products and there are no significant overlaps among all PCR products, a total of 200 to 250 pairs of arbitrary primers would be needed to exhaust the screening for all possible $S$. aureus genes. Therefore, the results described in this paper accounts for approximately $15 \%$ of the $S$. aureus genome. Four pairs of these primers were successful at generating PCR products, while the other 26 pairs of primers produced 5 to 15 DNA bands. Northern blot analysis of 19 selected PCR products confirmed that eight clones were uniquely or highly expressed in the predominant strain $\mathrm{A} 4$, and one clone was highly expressed in the rare strain L42 (data not shown). A BLAST search demonstrated that nine positive clones had matches within the $S$. aureus genomic DNA sequence database. The cDNA sequence from clone UH-12 contained an open reading frame (ORF) that had a $93 \%$ similarity to the $S$. aureus Fibronectin-binding protein B amino acid se-
Table 2. The clones differentially expressed in predominant and rare S. aureus strains (A4 vs. L42).

\begin{tabular}{ll} 
ID & BLAST Search Results (GenBank) \\
\hline UH-1/2 & $\begin{array}{l}\text { 678bp, } 99 \%(627 / 643) \text { identity to Staphylococcus aureus } \\
\text { lactose-specific transporter enzyme II DNA sequence. }\end{array}$ \\
UH-12 & $\begin{array}{l}421 \mathrm{bp}, 93 \%(319 / 341) \text { identity to } S \text {. aureus FnBP-B } \\
\text { DNA sequence. }\end{array}$
\end{tabular}

UH-4/2 532 bp, $94 \%$ (468/494) identity to a S. aureus hypothetical protein DNA sequence.

UH-19 $342 \mathrm{bp}, 97 \%$ (285/291) identity to toxic anion resistance protein homologue DNA sequence in $S$. aureus.

UH-6/1 422 bp, 96\% (369/383) identity S. aureus aspartatesemialdehyde dehydrogenase DNA sequence.

UH-3/6 $493 \mathrm{bp}, 97 \%$ (451/464) identity to a $S$. aureus hypothetical protein DNA sequence.

UH-2 $594 \mathrm{bp}, 95 \%(552 / 579)$ identity to a $S$. aureus putative serine-threonine rich antigen sequence.

IH-4/7 338 bp, 98\% (296/301) identity to $S$. aureus inositolmonophosphate dehydrogenase DNA sequence.

LIH-13 716 bp, 98\% (698/707) identity to a S. aureus hypothetical protein DNA sequence.

quence. A different clone, UH-1/2, contained an ORF that had a $99 \%$ similarity to the $S$. aureus lactose-specific transporter EII amino acid sequence. The remaining clones included ORF that closely matched other $S$. aureus genes (Table 2).

To obtain a quantitative measure on whether EII was differentially expressed in milk, three prevalent and three rare strains known to have differentially expressed genes, were analyzed using QC RT-PCR. As shown in Figure 1, the prevalent strains produced significantly more EII transcripts than the rare strains,



Figure 1. Enzyme II (EII) mRNA expression between prevalent (ם) and rare ( $\square$ ) Staphylococcus aureus strains grown in UHT milk. Data are expressed as means + standard error for three strains per group in duplicate assays. *Indicate significant differences between groups $(P<0.05)$. 
confirming the results obtained from differential display PCR and Northern blot. Because EII is the lactose transporter in $S$. aureus, its expression may affect growth in an environment rich in lactose, such as milk. Therefore, we tested the growth of a total of 18 stains (nine prevalent and nine rare) in UHT milk over $12 \mathrm{~h}$ while growing at $37^{\circ} \mathrm{C}$. The data in Figure 2 show that prevalent strains grew better than rare strains in UHT milk, reaching significantly higher densities in lateexponential and stationary phases, although growth rates remained unchanged. Based on these data, we hypothesized that increased EII mRNA expression is responsible for improved growth in a lactose-rich environment.

\section{Correlation Between Ell mRNA Expression and Growth}

To determine how carbohydrate source affects EII mRNA expression, we conducted QC RT-PCR on 18 strains (nine prevalent and nine rare). Because the concentration of lactose is known to vary significantly in milk (Kitchen, 1981), it was important to use a medium in which the carbohydrate source could be controlled. Thus, TSB was modified to contain $13.89 \mathrm{~m} M$ glucose, $13.89 \mathrm{~m} M$ glucose and $13.89 \mathrm{~m} M$ lactose, $13.89 \mathrm{~m} M$ lactose, or $136 \mathrm{~m} M$ lactose. We chose a concentration of $136 \mathrm{~m} M$ lactose to simulate milk, since it contains $136 \mathrm{~m} M$ lactose on average (Kitchen, 1981). In addition, $13.89 \mathrm{~m} M$ lactose was chosen to determine whether a lower lactose concentration would affect EII mRNA expression, and to match the concentration of glucose found in stock TSB. QC RT-PCR revealed that prevalent strains produce significantly more EII transcripts when grown in media containing $13.89 \mathrm{mM}$ and 136

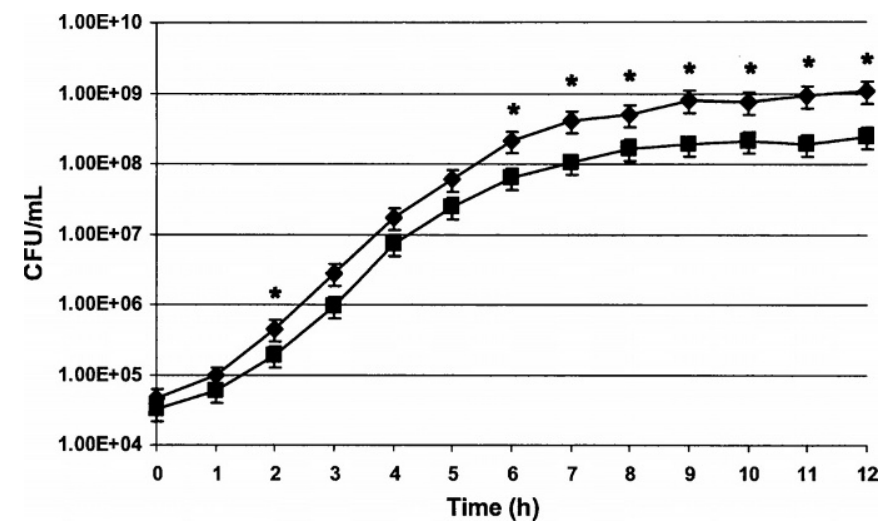

Figure 2. Growth curve of prevalent $(\bullet)$ and rare (ם) Staphylococcus aureus strains grown in UHT milk. Each data point represents the mean \pm standard errors for nine strains per prevalence group in duplicate assays. *Indicate significant differences between groups per time point $(P<0.05)$.

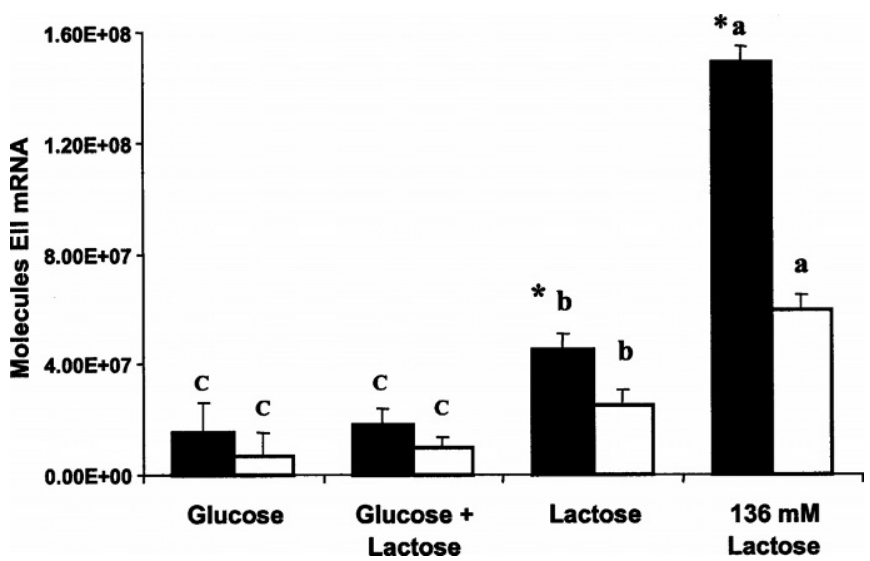

Figure 3. Enzyme II (EII) mRNA expression between prevalent - and rare ( $\square$ ) Staphylococcus aureus strains grown in tryptic soy broth containing $13.89 \mathrm{~m} M$ glucose, $13.89 \mathrm{~m} M$ glucose and $13.89 \mathrm{~m} M$ lactose, $13.89 \mathrm{mM}$ lactose, or $136 \mathrm{mM}$ lactose. Data are expressed as means \pm standard error for nine strains per group in duplicate assays. *Indicate significant differences between prevalent and rare $S$. aureus strains $(P<0.05))^{\mathrm{a}, \mathrm{b}, \mathrm{c}}$ Indicate significant differences with respect to culture media $(P<0.05)$.

$\mathrm{m} M$ lactose (Figure 3), demonstrating that lactose affects EII transcription. No significant differences in EII transcript production were observed between prevalent and rare strains grown in media containing both glucose and lactose, or glucose alone. Figure 3 also reveals a dose response in EII mRNA expression with respect to the percentage of lactose in the media, in both prevalent and rare strains. By increasing lactose concentration, EII transcript production also increases. Furthermore, both prevalent and rare strains produce significantly more EII transcripts when grown in $136 \mathrm{~m} M$ lactose, than when grown in $13.89 \mathrm{~m} M$ lactose with no glucose present.

To determine whether EII mRNA expression correlates with growth, the 18 isolates also were analyzed for their ability to grow in media containing different concentrations of glucose and lactose. When the strains were grown in media containing glucose, only minor differences appeared (Figure 4), indicating that both populations could utilize glucose efficiently. Conversely, prevalent strains displayed improved growth compared to rare strains during growth in media containing only lactose (Figure 4). Growth in $136 \mathrm{mM}$ lactose reveals that rare strains require approximately an additional hour of growth during late-exponential phase to attain similar densities achieved by prevalent strains. The ability of prevalent strains to begin a shiftdown in growth rate earlier may contribute to their virulence by increasing toxin production (e.g., TSST-1) before rare strains (Timmins and Holland, 1999). 


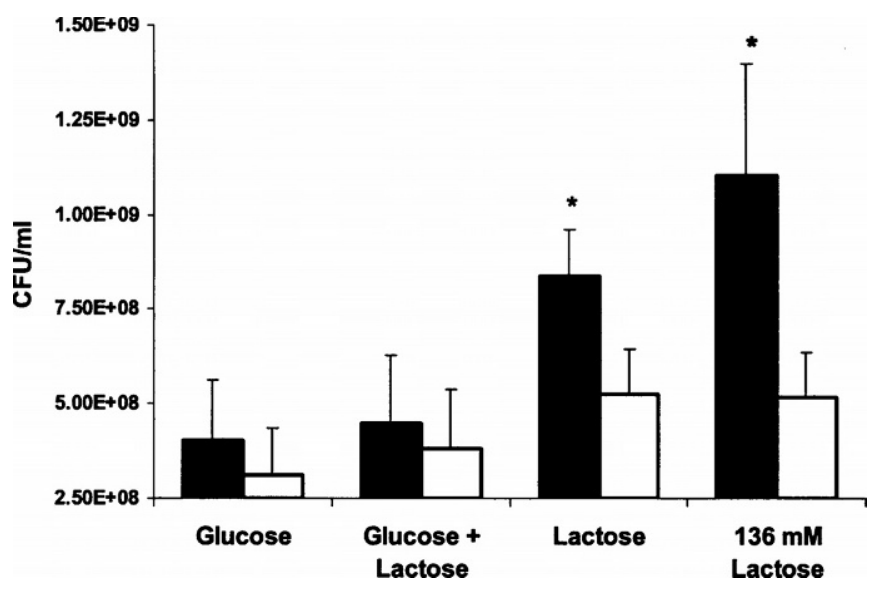

Figure 4. Growth comparison of prevalent $(\square)$ and rare $(\square)$ Staphylococcus aureus strains grown in tryptic soy broth containing 13.89 $\mathrm{m} M$ glucose, $13.89 \mathrm{~m} M$ glucose and $13.89 \mathrm{~m} M$ lactose, $13.89 \mathrm{~m} M$ lactose, or $136 \mathrm{~m} M$ lactose after $8 \mathrm{~h}$. Each data point represents the mean \pm standard error for nine strains per prevalence group in duplicate assays. *Indicate significant differences between prevalent and rare $S$. aureus strains per time point $(P<0.05)$.

\section{Impact of Ell Mutagenesis on Growth}

To establish whether EII expression directly affects growth, EII of the prevalent strain, CZ8, was mutated by inserting an antibiotic gene through allelic exchange, and verified by PCR. Mutagenesis of EII resulted in significantly lower expression of EII transcripts compared with wild-type (Figure 5), demonstra-

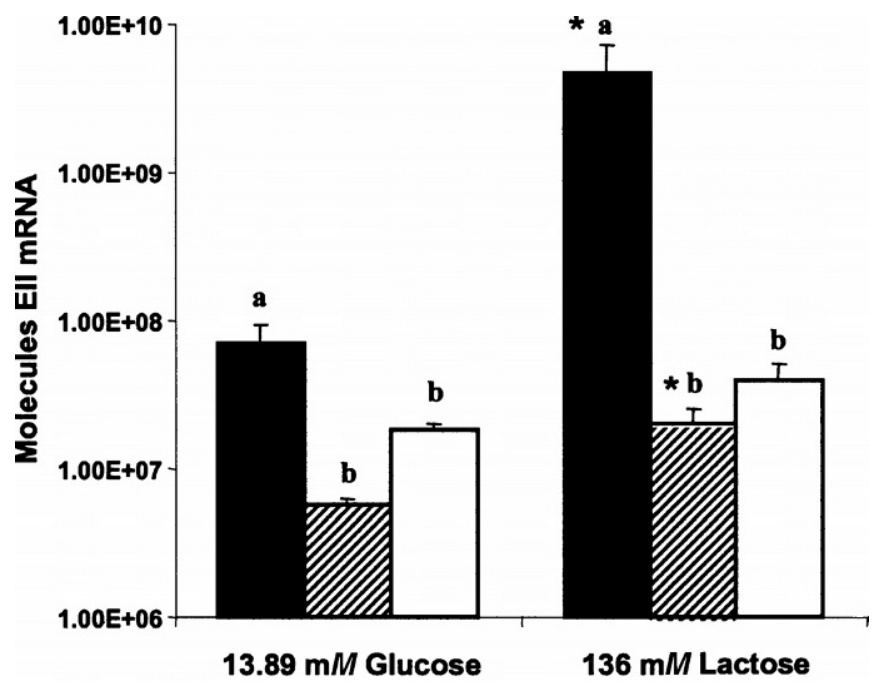

Figure 5. Enzyme II (EII) mRNA expression among prevalent (ם), EII mutant (striped bar), and rare ( $\square$ ) Staphylococcus aureus grown in tryptic soy broth containing either $13.89 \mathrm{mM}$ glucose or $136 \mathrm{~m} M$ lactose. Data are expressed as means \pm standard error in triplicate assays. ${ }^{\text {a,b }}$ Indicate significant differences between $S$. aureus strains $(P<0.05)$. *Indicate significant differences with respect to growth media $(P<0.05)$.

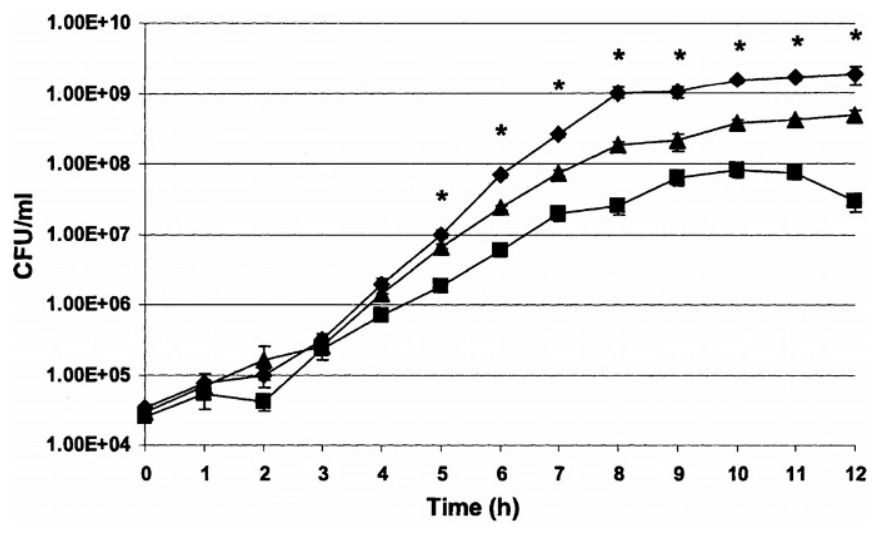

Figure 6. Growth curve of prevalent $(\diamond)$, Enzyme II (EII) mutant (৯), and rare (ם) Staphylococcus aureus grown in UHT milk. Each data point represents the mean \pm standard error of quadruplicate assays. *Indicate significant differences between prevalent and mutant $S$. aureus per time point $(P<0.05)$.

ting that the mutation was successful in altering expression of the EII gene. The mutant also displayed abrogated growth in media containing lactose, confirming that EII mRNA expression alters growth. In UHT milk, the mutant attained significantly lower growth densities than the wild-type prevalent strain (Figure 6). Conversely, few differences were observed between wild-type and mutant when grown in media containing glucose (Figure 7), demonstrating that the EII mutation is specific to growth in lactose. As with UHT milk, the mutant did not grow as well as the wild type in $136 \mathrm{mM}$



Figure 7. Colony-forming units of prevalent (ם), Enzyme II (EII) mutant (striped bar), and rare ( $\square$ ) Staphylococcus aureus grown in tryptic soy broth containing $13.89 \mathrm{~m} M$ glucose or $136 \mathrm{~m} M$ lactose after $8 \mathrm{~h}$. Each data point represents the mean \pm standard error of quadruplicate assays. *Indicate significant differences between prevalent and mutant $S$. aureus per time point $(P<0.05)$. 
lactose (Figure 7). Finally, the EII mutant displayed significantly reduced phospho- $\beta$-galactosidase activity, further demonstrating that the mutation in EII has a direct effect on lactose (Figure 8).

\section{DISCUSSION}

In this study, we were able to identify differentially expressed genes among bovine mastitis-causing $S$. aureus strains using differential display PCR. The screening presented in this paper is representative of approximately $15 \%$ of the $S$. aureus genome. Thus, further analysis of the $S$. aureus genome would likely identify additional differentially expressed genes than those presented in this report. Nevertheless, the identification of Fibronectin-binding protein $\mathrm{B}$ as a virulence factor in this experiment proved that differential display PCR could be a valuable tool to study other potential $S$. aureus virulence factors, as strong evidence exists to suggest that Fibronectin-binding protein B is a relevant virulence factor in S. aureus mastitis (Mamo et al., 1994; Sutra and Poutrel, 1994; Mamo et al., 1995; Park et al., 1999). The gene for the lactose-specific permease EII, $l a c E$, also was identified as a differentially expressed gene. We chose to focus on EII, because it is responsible for active transport of lactose in S. aureus, which is the primary carbohydrate in milk (Postma et al., 1993). To our knowledge, this is the first report to suggest an association between EII expression and mastitis by affecting the growth of $S$. aureus in a lactose-rich environment, such as milk.

The results from this study show that EII mRNA expression is regulated by carbohydrate source. Transcription of the lac operon, and consequently EII, is controlled by the catabolite repressor and lac repressor (Oskouian and Stewart, 1987). In the presence of glucose, the catabolite repressor prevents transcription by binding to the promoter site of the lac operon (Oskouian and Stewart, 1990), thus corroborating the observed decrease in EII mRNA expression in the presence of glucose. Furthermore, lac repressor binding of the lac promoter region is inhibited in the presence of galactose-6-phosphate, a byproduct of lactose catabolism (Morse et al., 1968). Hence, the higher the concentration of lactose, the less likely the lac repressor will be able to prevent transcription of the lac genes. This theory is substantiated by our observations of a dose response in EII mRNA expression to an increase in lactose concentration.

In this study, we found that EII affects growth when $S$. aureus is cultured in UHT milk and media rich in lactose. While we found that growth rates were similar between prevalent and rare strains, prevalent strains appeared to enter stationary phase sooner. The ability

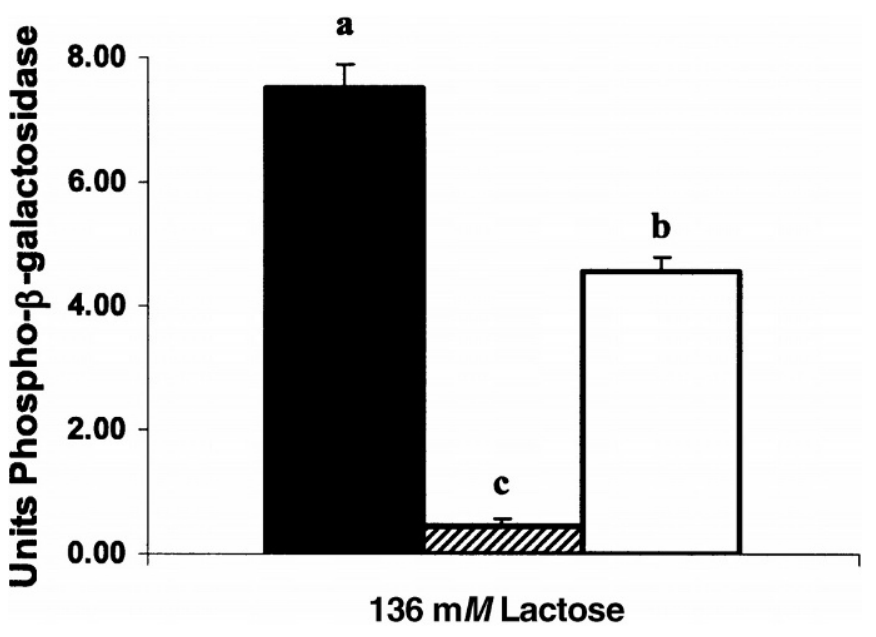

Figure 8. Activity of phospho- $\beta$-galactosidase by prevalent (ם), Enzyme II (EII) mutant (striped bar), and rare ( $\square$ ) Staphylococcus aureus grown in tryptic soy broth containing $136 \mathrm{~m} M$ lactose. Units of phospho- $\beta$-galactosidase were measured using $O$-nitrophenol $\beta$-Dgalactopyranoside in bacteria grown to mid-exponential phase. The data represent means + standard errors of three independent experiments. ${ }^{\text {a,b,c }}$ Indicate significant differences between groups $(P<0.05)$.

to enter stationary phase earlier may contribute to virulence by allowing the bacteria to devote more energy into virulence factor production rather than growth. For example, production of known virulence factors such as $\alpha$-toxin and TSST-1 do not reach maximum levels until $S$. aureus exits exponential growth (Coleman and Abbas-Ali, 1977; Timmins and Holland, 1999). Prevalent $S$. aureus strains achieved significantly higher growth densities than rare strains in UHT milk. Increased growth correlated with EII expression in milk, but the contribution of other milk components besides lactose cannot be overlooked. The mutation in EII was not enough to reduce the growth of the mutated prevalent strain to that of the selected rare strain (Figure 7), suggesting that other components contribute to the growth of these $S$. aureus strains in milk. For instance, one study found that certain enterotoxin-producing strains of $S$. aureus grew better in milk fat (cream) than others (Halpin-Dohnalek and Marth, 1989). Moreover, the compositional changes brought about during mastitis influence how $S$. aureus grows, since heme components and casein degradation play a role in improved S. aureus growth (Mattila et al., 1984; Kaartinen and Sandholm, 1987). Therefore, EII is likely to be one of many factors that can influence growth in milk.

The EII effect on growth in milk is confounded by the fact that lactose concentration is known to vary (Kitchen, 1981). For this reason, TSB was useful because the carbohydrate concentration can be better controlled. Growth in this media resulted in curves distinct from UHT milk, possessing less pronounced differences. 
Nevertheless, prevalent strains appeared to grow better than rare strains in media containing lactose as the only carbohydrate. Interestingly, growth in media that contained glucose resulted in the fewest differences, suggesting to us that EII was responsible for the observed differences between prevalent and rare strains. Additionally, the mutation in EII abrogated growth in media containing only lactose, but not in media containing glucose, further substantiating that EII expression affects growth.

To elucidate whether EII expression is directly responsible for altering growth, we disrupted the lacE gene in a prevalent $S$. aureus strain. Mutagenesis of $l a c E$ resulted in lower growth densities compared with the wild-type strain when grown in lactose. Consistent with our previous observations, the $l a c E$ mutant grew as well as wild-type $S$. aureus in media containing glucose. These results confirm that the disruption was specific for lactose metabolism, and that the lactose-specific EII does not play a role in glucose metabolism in $S$. aureus, as it relates to growth. Disruption of lacE also resulted in decreased expression of EII transcripts and phospho- $\beta$-galactosidase activity. Taken together, these data confirm that growth is linked to EII expression in lactose. Without the lactose-specific EII to transport lactose across the bacterial membrane, PTS uptake of the carbohydrate would be prevented (Postma et al., 1993). In the absence of intracellular lactose, galactose6-phosphate would not be generated. Consequently, transcription of the lac operon would not be initiated (Morse et al., 1968). Furthermore, the mutant was able to reach higher densities than the selected rare strain, suggesting to us that this rare strain may have deficiencies in other carbon metabolisms beyond that of lactose metabolism.

Because the lac operon regulates itself through a repressor and promoter, it is possible that a variation in the concentration of promoter sites, or repressor molecules, could result in variation in the remaining lac operon (Oskouian and Stewart, 1990). For example, increasing the concentration of lac promoter transcripts could titrate out the lactose repressor molecule, resulting in constitutive expression of the lac genes (Oskouian and Stewart, 1990). Thus, the results observed in this study may be due to differential expression of the repressor or promoter rather than just EII. Additionally, many gram-positive bacteria contain a global catabolite control protein (CcpA), which could play a role in the differential expression of the lac operon between prevalent and rare strains (Stewart, 1993; Henkin, 1996; Saier, 1996; Saier et al., 1996). However, the role of CcpA has yet to be defined and characterized in $S$. aureus. Regardless, EII remains valuable, as it is the only lac component to be surface- associated and responsible for transporting lactose into the cell from its surroundings (Breidt et al., 1987; Kowolik and Hengstenberg, 1998). Consequently, EII could be immunologically targeted with antibodies, along with other known virulence factors to create a subunit vaccine.

Differential display PCR has successfully identified differentially expressed genes between prevalent and rare $S$. aureus strains, which may contribute to observed variations in virulence. Increased growth rate is one of many factors that contribute to $S$. aureus virulence in mastitis (Chesbro et al., 1968; White et al., 1980; Odierno et al., 1994). Staphylococcus aureus growth is in large part due to the availability of simple carbohydrates, such as glucose and lactose. Consequently, this study is the first to suggest that the lactose transporter, EII, may play a role in mastitis virulence as EII expression affects growth in a lactose-rich environment. Future research will focus on determining whether EII affects in vivo virulence. EII may be useful in the development novel therapeutic strategies against $S$. aureus mastitis.

\section{ACKNOWLEDGMENTS}

We thank Richard Novick for providing $S$. aureus RN4220. We also thank Chia Lee for providing the vector pCL52.1. Funding for this research was provided by grants from the Pennsylvania Department of Agriculture, Animal Health Commission (ME448430 and ME 440676).

\section{REFERENCES}

Aarestrup, F. M., C. A. Dangler, and L. M. Sordillo. 1995. Prevalence of coagulase gene polymorphism in Staphyococcus aureus isolates causing bovine mastitis. J. Clin. Microbiol. 59:124-128.

Achour, Y. B., M. Chenik, H. Louzir, and K. Dellagi. 2002. Identification of a disulfide isomerase protein of Leishmania major as a putative virulence factor. Infect. Immun. 70:3576-3585.

Altschul, S. F., W. Gish, W. Miller, E. W. Myers, and D. J. Lipman. 1990. Basic local alignment search tool. J. Mol. Biol. 215:403-410.

Baumgartner, A., J. Nicolet, and M. Eggimann. 1984. Plasmid profiles of Staphylococcus aureus causing bovine mastitis. J. Appl. Bacteriol. 56:159-163.

Breidt, F. J., W. Hengstenberg, U. Finkeldei, and G. C. Stewart. 1987. Identification of the genes for the lactose-specific components of the phosphotransferase system in the lac operon of Staphylococcus aureus. J. Biol. Chem. 262:16444-16449.

Chesbro, W. R., I. Wamola, and C. H. Bartley. 1968. Correlation of virulence with growth rate in Staphylococcus aureus. Can. J. Microbiol. 15:723-729.

Coleman, G., and B. Abbas-Ali. 1977. Comparison of the patterns of increased in alpha-toxin and total extracellular protein by Staphylococcus aureus (Wood 46) grown in media supporting widely differing growth characteristics. Infect. Immun. 17:278-281.

Goh, S., S. K. Byrne, J. L. Zhang, and A. W. Chow. 1992. Molecular typing of Staphylococcus aureus on the basis of coagulase gene polymorphisms. J. Clin. Microbiol. 30:1642-1645.

Halpin-Dohnalek, M. I., and E. H. Marth. 1989. Growth and production of enterotoxin A by Staphylococcus aureus in cream. J. Dairy Sci. 72:2266-2275. 
Hengstenberg, W., W. K. Penberthy, and M. L. Morse. 1970. Purification of the staphylococcal 6-phospho- $\beta$-D-galactosidase. Eur. J. Biochem. 14:27-32.

Henkin, T. M. 1996. The role of CcpA transcriptional regulator in carbon metabolism in Bacillus subtilis. FEMS Microbiol. Lett. 135:9-15.

Kaartinen, L., and M. Sandholm. 1987. Regulation of plasmin activation in mastitic milk. Correlation with inflammatory markers and growth of Streptococcus agalactiae. Zentralbl. Veterinarmed. [B]. 34:42-50.

Kitchen, B. J. 1981. Review of the progress of dairy science: bovine mastitis: Milk compositional changes and related diagnostic tests. J. Dairy Res. 48:167-188.

Kowolik, C. M., and W. Hengstenberg. 1998. The lactose transporter of Staphylococcus aureus: Overexpression, purification and characterization of the histidine-tagged domains of IIC and IIB. Eur. J. Biochem. 257:389-394.

Kreiswirth, B. N., S. Lofdahl, M. J. Betley, M. O'Reilly, P. M. Schlievert, M. S. Bergdoll, and R. P. Novick. 1983. The toxic shock syndrome exotoxin structural gene is not detectably transmitted by a prophage. Nature 305:709-712.

Lengeler, J. W., K. Jahreis, and U. F. Wehmeier. 1994. Enzyme II of the phosphoenolpyruvate-dependent phosphotranferase system: Their structure and function in carbohydrate transport. Biochem. Biophys. Acta 1188:1-28.

Liang, P., and A. B. Pardee. 1992. Differential display of eukaryotic messenger RNA by means of the polymerase chain reaction. Science 257:967-971.

Lin, W. S., T. Cunneen, and C. Y. Lee. 1994. Sequence analysis and molecular characterization of genes required for the biosynthesis of type 1 capsular polysaccharide in Staphylococcus aureus. J. Bacteriol. 176:7005-7016.

Mamo, W., P. Jonsson, J. Flock, M. Lindberg, H. P. Muller, T. Wadstrom, and L. Nelson. 1994. Vaccination against Staphylococcus aureus mastitis; immunological response of mice vaccinated with fibronectin binding proteins (FnBPs) to challenge with $S$. aureus. Vaccine 12:988-992.

Mamo, W., P. Jonsson, and H. P. Muller. 1995. Opsinization of Staphyloccus aureus with fibronectin-binding protein antiserum induces protection in mice. Microb. Pathog. 19:49-55.

Matthews, K. R., S. J. Kumar, S. A. O'Conner, R. J. Harmon, J. W. Pankey, L. K. Fox, and S. P. Oliver. 1994. Genomic fingerprints of Staphylococcus aureus of bovine origin by polymerase chain reaction-based DNA fingerprinting. Epidemiol. Infect. 112:177186.

Mattila, T., P. Maisi, and M. Sandholm. 1984. Haem compounds as bacterial growth promoters in whey: A possible application to bovine mastitis. Res. Vet. Sci. 36:52-56.

Morse, M. L., K. L. Hill, J. B. Egan, and W. Hengstenberg. 1968. Metabolism of lactose by Staphylococcus aureus and its genetic basis. J Bacteriol. 95:2270-2274.

Mullarky, I., C. Su, N. Frieze, Y. H. Park, and L. M. Sordillo. 2001. Staphylococcus aureus agr genotypes with enterotoxin production capabilities can resist neutrophil bactericidal activity. Infect. Immun. 69:45-51.

Musser, J. M., P. M. Schlievert, A. W. Chow, P. Ewan, B. N. Kreiswirth, V. T. Rosdahl, A. S. Naidu, W. Witte, and R. K. Selander. 1990. A single clone of Staphylococcus aureus causes the majority of cases of toxic shock syndrome. Proc. Natl. Acad. Sci. USA 87:225-229.

Novick, R. P., H. F. Ross, S. J. Projan, J. Kornblum, B. Kreiswirth, and S. Moghazeh. 1993. Synthesis of staphylococcal virulence factors is controlled by a regulatory RNA molecule. EMBO J. $12: 3967-3975$
Odierno, L., G. Risatti, A. Calzolari, J. A. Giraudo, H. Gonzalez Quintana, and R. Nagel. 1994. Pathogenicity in mice of Staphylococcus aureus mutants deficient in exoprotein synthesis. Vet. Microbiol. 41:249-258.

Oskouian, B. and G. C. Stewart. 1987. Cloning and characterization of the repressor gene of the Staphylococcus aureus lactose operon. J. Bacteriol. 169:5459-5465.

Oskouian, B., and G. C. Stewart. 1990. Repression and catabolite repression of the lactose operon of Staphylococcus aureus. J. Bacteriol. 172:3804-3812.

Park, H. M., H. S. Yoo, T. H. Oh, D. Kim, and H. R. Han. 1999 Immunogenicity of alpha-toxin, capsular polysaccharide (CPS) and recombinant fibronectin-binding protein (r-FnBP) of Staphylococcus aureus in rabbit. J. Vet. Med. Sci. 61:995-1000.

Peng, H. L., R. P. Novick, B. Kreiswirth, J. Kornblum, and P. Schlievert. 1988. Cloning, characterization, and sequencing of an accessory gene regulator (agr) in Staphylococcus aureus. J. Bacteriol. 170:4365-4372.

Postma, P. W., J. W. Lengeler, and G. R. Jacobson. 1993. Phosphoenolpyruvate: carbohydrate phosphotransferase systems of bacteria. Microbiol. Rev. 57:543-594.

Reizer, J., M. H. Saier, Jr., J. Deutscher, F. Grenier, J. Thompson, and W. Hengstenberg. 1988. The phosphoenolpyruvate:sugar phosphotransferase system in Gram-positive bacteria: Properties, mechanism, and regulation. Crit. Rev. Microbiol. 15:297338

Rindi, L., N. Lari and C. Garzelli. 1999. Search for genes potentially involved in Mycobacterium tuberculosis virulence by mRNA differential display. Biochem. Biophys. Res. Commun. 258:94-101.

Saier, M. H., Jr. 1996. Cyclic AMP-independent catabolite repression in bacteria. FEMS Microbiol. Lett. 138:97-103.

Saier, M. H. Jr., S. Chauvaux, G. M. Cook, J. Deutscher, I. T. Paulsen, J. Reizer, and Y. Y. Ye. 1996. Catabolite repression and inducer control in Gram-positive bacteria. Microbiology 142:217-230.

Saulnier, P., C. Bourneix, G. Prevost, and A. Andremon. 1993. Random amplified polymorphic DNA assay is less discriminant than pulse-field gel electrophoresis for typing strains of methicillinresistant Staphylococcus aureus. J. Clin. Microbiol. 31:982-985.

Slanetz, L. W., and C. H. Bartley. 1962. Bacteriophage and serological typing of staphylococci from bovine mastitis. J. Infect. Dis. 110:238-245.

Stewart, G. C. 1993. Catabolite repression in the gram-positive bacteria: Generation of negative regulators of transcription. J. Cell. Biochem. 58:25-28.

Su, C., C. Herbelin, N. Frieze, O. Skardova, and L. M. Sordillo. 1999. Coagulase gene polymorphism of Staphylococcus aureus isolates from dairy cattle in different geographical areas. Epidemiol. Infect. 122:329-336.

Su, C., and L. M. Sordillo. 1998. A simple method to enrich mRNA from total prokaryotic RNA. Mol. Biotechnol. 10:83-85.

Sutra, L., and B. Poutrel. 1994. Virulence factors involved in the pathogenesis of bovine intramammary infections due to Staphyloccus aureus. J. Med. Microbiol. 40:79-89.

Thomson-Carter, F. M., P. E. Carter, and T. H. Pennington. 1989. Differentiation of staphylococcal species and strains by ribosomal RNA gene restriction patterns. J. Gen. Microbiol. 135:2093-2097.

Timmins, B. S., and K. T. Holland. 1999. Shift-down in growth rate rather than high cell density induces toxic shock syndrome toxin1 gene expression in Staphylococcus aureus. FEMS Microbiol. Lett. 172:173-177.

White, E. A., M. J. Paape, B. T. Weinland, and I. H. Mather. 1980. Virulence of three strains of Staphylococcus aureus isolated from clinically infected bovine mammary glands. J. Dairy Sci. 63:1128-1133. 